assumes, however, that the live load is suddenly applied. If the time taken to apply the load is comparable with the period of vibration of the bridge, this is no longer true, and however fast a train is travelling the time taken to apply the load is con siderable, and it is not surprising that actual measurements of deflection show that the stresses due to a moving train are in many cases but little greater than those due to the same load when at rest.

One speaker in the discussion at Hull emphasised the importance of minimising corrosion and looked forward to the possible use of stainless steel for bridges; in the meanwhile he had great hopes of the cement gun, by means of which a thin coating of cement is applied to the iron work.

A paper by Mr. J. S. Wilson and Prof. B. P. Haigh dealt very fully with the influence of rivet holes, not only in bridges but in steel structures in general This is of importance in the present controversy because of the uncertainty of the allowance to be made for the rivet holes in calculating the stress due to any given load. Calculation indicates that very high stresses should occur in the neighbourhood of rivet holes, but from a large number of experiments the authors came to the conclusion that "the metals used in practice have a ductility and other qualities which render them able to eliminate or accommodate these high stresses."

The various papers read and the remarks made by the speakers in the discussion all tended to show that the actual stresses occurring in bridge work are considerably lower than those usually calculated, and that past and present practice allows an ample factor of safety.

\title{
The Alps of Chinese Tibet and their Geographical Relations. ${ }^{1}$
}

By Prof. J. W. Gregory, F.R.S., and J. C. Gregory. SOUTH-EASTERN Asia is a region of interesting
geographical enigmas which deal with the contrast between south-eastern and south-western Asia, the eastern prolongation of the Himalaya, the place of the mountains of south-western China in the mountain system of Asia, and the remarkable arrangement of the rivers of south-eastern Tibet, which has been described as one of the most extraordinary features of the earth's land surface. These problems are intimately connected with the formation of the basin of the Indian Ocean.

"Seek knowledge," said Mohammet, " even if it is found in China," and in accordance with that injunction of the Prophet the authors landed at Bhamo on the upper Irawadi, 50 miles from the Chinese frontier. This port of departure was selected in obedience to the principle of the Burmese proverb that an old road is a fast road; for the road from Bhamo to the Treaty Port of Tengyueh in southwestern China is one of the trade routes of Asia which has been used since prehistoric times. At Tengyueh the Indians who had accompanied the expedition over the frontier mountains were sent back, a Chinese staff being engaged; permission was obtained to proceed to Likiang, the administrative headquarters near the borders of Chinese Tibet. As part of this road was across unsurveyed country in which brigandage was rife, the authorities insisted on the money of the expedition being sent on either by draft or along the main road.

The expedition arrived at Likiang before its money, and a further check was threatened by the refusal of the magistrate to allow the expedition to proceed further north. This decision was found to be in obedience to instructions from the provincial capital, but the magistrate of Likiang ultimately agreed to let the expedition proceed, provided he had no further instructions from the capital, on the receipt of a letter stating that the travellers were going on in spite of his warning and entirely at their own risk. Meanwhile a Chinese merchant in the city had agreed to advance half the amount of the draft, and as soon as this was paid the expedition hurried northward into Chinese Tibet to get beyond recall.

The path taken descended from the plateau into the valley of the Yangtze-kiang where, though 2400 miles from the sea, it is still a great river, and was then in high flood owing to the melting of the Tibetan snows. The structure of this valley and of its two parallel neighbours, the Mekong and Salween, was studied in a series of journeys along these rivers and

${ }^{x}$ Substance of a paper read before the Royal Geographical Society on December Ir.

NO. 2772 , VOL. I IO] over the mountains between them. The inhabited districts along the Salween were smitten with famine owing to the failure of the previous harvest, and work there was impossible. The range of Kagurpu with its pyramidal snow-clad peaks and its great glaciers was inaccessible, as its crest is the forbidden frontier between Chinese and autonomous Tibet. Hence for a study of the mountain structure of this region the expedition turned eastward to the peaks and glaciers between the Mekong and the Yangtzekiang, crossing passes from $x 6,000$ to $x 8,000 \mathrm{ft}$. in height. Bad weather frustrated the attempt to explore the glaciers of Peima-shan and heavy floods hampered the return march to Likiang. Wide tracts of country around Tali-fu, the former Muslim capital which had withstood a siege of eighteen years during the-Civil War of I855-73, were flooded owing to the abnormally heavy rains. The caravan had to enter the city by climbing over the city wall, as the north gate was closed to keep out the mischievous spirits from the north which had brought the excessive rains that were threatening the country with famine. From Tali the expedition returned by the main road across Yunnan to the Irawadi in Burma.

The observations made during the journey show that the geography of Chinese Tibet is the result of mountain formation at two distinct periods. The deep valleys with their intermediate ranges, which are the most conspicuous topographic features, are the result of mountain movements of the age of the Coal Measures. These ancient movements gave the country a geographical grain trending north and south, and the Indo-Malayan mountains have been formed by the excavation of valleys along the weaker layers of the grain. Mountains belonging to a relatively modern date have been formed contemporary with the upheaval of the Alps and Himalaya. The high peaks of Chinese Tibet rising over 24,000 ft. in height are due to these later uplifts. The main axis of the Himalaya passes through Chinese Tibet and is probably continued through the Nan-shan of southern China to the Pacific. The Burmese and Malay mountain arcs, which are the same age as the Himalaya, represent a loop to the south of the main mountain axis like the Persian loop in south-western Asia and the Apennine Ioop in Europe. The great rises on the floor of the Pacific, which reach the surface in the Hawaiian Islands and the coral islands of Polynesia, are probably the continuation of these two mountain lines, being like them due to the pressure interacting between the northern cap of the world and the tropical or subtropical zone. 
The enigma of the three parallel rivers is explained as due to their valleys having been worn out along clefts through which the drainage from south-eastern Tibet was enabled to escape through the mountain rim of Chinese Tibet. This rim had been formed by the Himalayan movements which were due to the intense compression of the crust; on the relief from that pressure the mountain ranges were broken by transverse clefts, and large blocks sank between a network of fractures. The basins formed by these subsidences gave the rivers great powers of enlarging their channels and thus of excavating the deep steepsided valleys which are now the most conspicuous features in the topography of south-western China.

\section{The Present Position of the Whaling Industry. ${ }^{1}$}

W HALING has been practised as an industry for some centuries. The pursuit of the Atlantic right whale was carried on in the Bay of Biscay at an early date, and was active at least so long ago as the twelfth century. The Greenland right whale was hunted in three areas, at successive periods, at first off Spitsbergen from about I6ro, when few Atlantic right whales were left, then in Davis Straits from about $17 \times 9$, and finally in the North Pacific and Bering Sea from about 1840 . The sperm whale, which occurred in the whole of the tropical belt, though by no means restricted to this area, was hunted from about $\times 7 \times 2$.

The successful introduction of the modern harpoongun, with a harpoon carrying an explosive charge, dates from $\mathrm{r} 865$, and has revolutionised whaling, by making it possible to capture the large and swift rorquals or fin whales. Modern whaling is concerned mainly with the humpback whale, the fin whale, and the blue whale, all of which are widely distributed in nearly all seas, although it is not certain whether each of these whalers' names indicates the same species in all parts of the world. After rorquals had been hunted in such localities as the Varanger

${ }^{1}$ Substance of a paper read before the Association of Economic Biologists by Sir Sidney F. Harmer, F.R.S., on November Io.
Fjord, Newfoundland, Iceland, the British and Norwegian coasts, and elsewhere, whaling on an unprecedented scale commenced off the edge of the Antarctic Continent in 1905, and is still being conducted energetically. The total catch in this area has exceeded 10,000 in a single year.

The principal whale-products of economic importance are: train-oil, sperm-oil, spermaceti, baleen, ambergris, whale meat, and the various forms of whale-meal or "guano." In a well-conducted factory all parts of the carcass are utilised.

With the exception of the Antarctic whaling, which has had a career of less than twenty years, whaling has been carried on consistently to an excessive amount, leading to the most serious reduction of the number of whales. The Atlantic and Greenland right whales were decimated almost to the point of extermination, the sperm whale industry has practically disappeared, and little remains now but the Antarctic whaling grounds. The efforts of all lovers of Nature should be directed to the restriction of whaling to an amount which is not inconsistent with the permanent preservation of these magnificent marine mammals and of the industry which they are so unfortunate as to support.
$\mathrm{I}^{\mathrm{N}}$ the current issue of Biometrika (vol. xiv. pts. i. and ii.) Dr. Kirstine Smith discusses the standard deviation of a coefficient of correlation computed from data derived from classes, members of which are mutually correlated, with special reference to the case of fraternal and parental correlations calculated from entries of siblings. She finds, inter alia, that the best determination of a fraternal correlation from a given number of observations is obtained by taking $(\mathrm{I}+\mathrm{r} / \mathrm{r})$ offspring individuals from each family, where $r$ is the fraternal correlation.

Mr. Egon S. Pearson contributes an important memoir on variations in personal equation. The experimental basis of the research was a series of five sets of measurements of different type; the form of sessional change, i.e. the resultant of factors operative within each series, is separated from the secular, or long period, change effective from one session to another; appropriate forms for the expression of each are discussed. It is evident that in the determination of the precise value of the correlation between successive judgments in a series, one has to reckon not only with physiological or psychological common factors, the organic basis of the correlation, but also with accidental errors which blur the record-the observational errors of some writers-and reduce the numerical value of the correlation. It is found that the correlations between successive judgments decrease approximately in geometrical progression with the number of intervals, a finding consistent with the assumption that there is little or no partial correlation between the observers' true estimates at intervals greater than one. The chief practical outcome of the work is to show that although "experience and accuracy may be gained by practice, it does not follow that the correlation between successive judgments will disappear."

\section{Studies.}

The memoir is not only of practical interest to all experimenters, but also contains several contributions to statistical algebra. In connexion with the work on pp. 37 et seq., a reference to the memoir of Anderson (Biometrika, x. 269) would have been in place, but no doubt Mr. Pearson will deal more fully with the literature of the subject in a sequel. He is to be congratulated on his first appearance in a field where one bearing his name must be judged by the highest possible standard.

Dr. Ernest Warren's paper concludes the account of work partly described in roI 7 concerning inheritance in the foxglove. Dr. Warren holds that " the evidence of the present investigation is therefore definitely against any general application of the theory of pure lines and of genotypes of any appreciable magnitude, and further it indicates that selective breeding within self-fertilised generations of a homogeneous race is capable of modifying that race to a marked degree."

Prof. Karl Pearson and Mr. Egon Pearson show how to find a general polychoric coefficient of correlation, i.e. to fit the "best" normal surface to data subject to the limitation that the marginal totals are exactly reproduced. The arithmetical work is heavy, and the suggestion is that a determination of the correlation ratio from the array means-not a laborious taskwill usually suffice.

Mr. James Henderson discusses the expansion of a function in tetrachoric functions, a matter of some importance to those who use the frequency systems favoured by Scandinavian mathematical statisticians.

It will be obvious that the fourteenth volume of Biometrika is as valuable to statisticians as its predecessors. 